\title{
Regional green total factor performance analysis of China's construction industry based on a unified framework combining static and dynamic indexes
}

Yan Li

Xi'an Jiaotong University School of Energy and Power Engineering

Jiangfeng Wang ( $\sim$ jfwang@mail.xjtu.edu.cn)

Xi'an Jiaotong University School of Energy and Power Engineering

Bin Liu

Xi'an Jiaotong University School of Energy and Power Engineering

Hongyan Li

Xi'an Jiaotong University School of Energy and Power Engineering

Yumin Guo

Xi'an Jiaotong University School of Energy and Power Engineering

Xinru Guo

Xi'an Jiaotong University School of Energy and Power Engineering

\section{Research Article}

Keywords: Construction industry in China, Global non-radial DEA approach, Green total factor efficiency, Green total factor productivity, Social welfare, Green development strategies

Posted Date: January 19th, 2022

DOI: https://doi.org/10.21203/rs.3.rs-1161479/v1

License: (c) (i) This work is licensed under a Creative Commons Attribution 4.0 International License.

Read Full License 


\title{
Regional green total factor performance analysis of China's construction industry based on a unified framework combining static and dynamic indexes
}

\author{
Yan $\mathrm{Li}^{a}$, Jiangfeng Wang ${ }^{a} *$, Bin Liu ${ }^{a, b}$, Hongyan $\mathrm{Li}^{a, b}$, Yumin $\mathrm{Guo}^{a}$, Xinru Guo ${ }^{a}$ \\ ${ }^{a}$ School of Energy \& Power Engineering, Xi'an Jiaotong University, Xi'an 710049, China \\ ${ }^{\mathrm{b}}$ Sinopec Green Energy Geothermal Development Co., Ltd, Xiong'an New Area, 071800, China
}

\section{Abstract}

It has important meaning to improve green total factor performance in the construction industry for China's green and high-quality development. In addition to the traditional desirable economic output and undesirable $\mathrm{CO}_{2}$ emission output, the indicators representing social welfare of China's construction industry were incorporated into the total factor framework. On this basis, a Global non-radial DEA approach was employed to explore the sources and the key factors leading to changes in regional green total factor performance of China's construction industry from both static and dynamic perspectives. Results showed that the lower energy efficiency and the lower $\mathrm{CO}_{2}$ emission efficiency were the main reasons for low level of green total factor efficiency. During the sample period, energy efficiency increased rapidly while capital efficiency remained almost unchanged. The green total factor productivity demonstrated an increasing trend, which was driven by technological progress rather than technical efficiency. An in-depth decomposition revealed that the deterioration of technical efficiency was mainly caused by the negative effect of $\mathrm{CO}_{2}$ emissions. Regional green total factor performance of China's construction industry demonstrated 
obvious spatial heterogeneity. Each province should comprehensively consider its own characteristics of green development in the construction industry to formulate the corresponding optimization strategy. These findings can help decision makers design specific policies on regional-oriented green development of China's construction industry.

Key words: Construction industry in China; Global non-radial DEA approach; Green total factor efficiency; Green total factor productivity; Social welfare; Green development strategies

* Corresponding author. Tel/ Fax: +86 02982668704

E-mail address: jfwang@mail.xjtu.edu.cn

\section{Nomenclature}

CRS Constant returns to scales

DMU Decision making unit

DEA Data envelopment analysis

SFA Stochastic frontier approach

SBM Slack-based measurement

$D D F \quad$ Directional distance function

$N D D F \quad$ Non-radial directional distance function

GNDDF Global non-radial directional distance function

E Energy consumption

L Labor 


\begin{tabular}{|c|c|}
\hline$K$ & Capital \\
\hline$O$ & Gross output value \\
\hline$F$ & Floor space under construction \\
\hline$P$ & Park green area \\
\hline$C$ & $\mathrm{CO}_{2}$ emissions \\
\hline$G E I$ & Green efficiency indicator \\
\hline EEI & Energy efficiency indicator \\
\hline$L E I$ & Labor efficiency indicator \\
\hline$K E I$ & Capital efficiency indicator \\
\hline CEI & $\mathrm{CO}_{2}$ emission efficiency indicator \\
\hline$G P I$ & Green productivity indicator \\
\hline$E P I$ & Energy productivity indicator \\
\hline$L P I$ & Labor productivity indicator \\
\hline KPI & Capital productivity indicator \\
\hline$C P I$ & Carbon productivity indicator \\
\hline$E C$ & Technical Efficiency Change \\
\hline$T C$ & Technological Change \\
\hline$C A B E E$ & China Association of Building Energy Efficiency \\
\hline$I P C C$ & Intergovernmental Panel on Climate Change \\
\hline MOHURD & Ministry of Housing and Urban-Rural Development \\
\hline
\end{tabular}




\section{Introduction}

As the world' s largest carbon emitter, China is willing to accept the weighty charge to tackle climate change. In the 'Paris Agreement', China pledged that the peak in $\mathrm{CO}_{2}$ emissions would be hit by the year 2030. Since 2020, the objective to peak $\mathrm{CO}_{2}$ emissions and achieve carbon neutrality have been reiterated on many vital occasions and incorporated into the overall layout of the ecological civilization construction of China. Thus, to achieve this goal, China should develop coordination and cooperation vigorously at the industrial level to pursue low-carbon development and better promote the comprehensive green transformation of society.

The construction industry has become a new engine of economic growth and urban development. With the rapid development of urban-rural construction, the issues of energy consumption and $\mathrm{CO}_{2}$ emissions have become increasingly prominent. (He et al., 2019). According to the China Building Energy Consumption Annual Report (CABEE, 2021), the life-cycle energy consumption and $\mathrm{CO}_{2}$ emissions of China's construction industry have grown at an annual growth rate of $6.6 \%$ and $6.3 \%$ respectively since 2005 . In 2018, energy consumption in the construction industry accounted for $46.5 \%$ of the total energy consumption of China, and $\mathrm{CO}_{2}$ emissions accounted for $51.2 \%$ of the total energy-related $\mathrm{CO}_{2}$ emissions of China. Large-scale construction has caused huge energy consumption and led to continuous high $\mathrm{CO}_{2}$ emissions, which has brought serious environmental impacts to social development. As pointed out by MOHURD (2021), the green development of China's construction industry has important meaning to the realization of high quality and sustainable 
development of society. Therefore, an analysis of the green performance of China's construction industry is necessary both in theory and in practice.

Indicators adopted to explore the static performance and dynamic change of green performance in construction industry can be measured under the single factor framework and the total factor framework, respectively. The single factor type was originally defined from one input-output system, such as energy intensity, Carbon productivity and carbon emission intensity (Ang, 1999; Hu and Liu, 2016; Zhang et al., 2014). In general, the single factor type can make calculation and make comparison easily, but the linkages with other production factors are ignored and the underlying technical efficiency fails to be reflected. On the contrary, the total factor framework is defined according to the actual production of multiple inputs and outputs. Energy efficiency under the total factor framework was initially defined by $\mathrm{Hu}$ and Wang (2006), and it rapidly got extensive attention from then.

The existing total factor performance are mainly measured by parametric methods and nonparametric methods. Compared with parametric method, the nonparametric model does not need to make assumptions on the function form in advance, which can avoid the influence of setting weights artificially on evaluation results. DEA, as a representative of nonparametric methods, has been widely used in different countries, sectors, economics and projects (Azadi et al., 2015; Ederer, 2015; Halkos and Tzeremes, 2009; Sueyoshi and Goto, 2014; Zhu et al., 2019). Initially, DEA was only adopted to measure the total factor efficiency from economic perspective. Mukherjee (2008a, b) investigated the energy efficiency in manufacturing sectors of India and United States. 
Zhang et al. (2011) analyzed the energy efficiency and its variation trend of 23 developing countries. However, the total factor performance evaluation that only considers the economic output without considering the importance of ecological environment may lead to the result distortion. To address this issue, the environmental factors began to be integrated into the measurement of the total factor performance by an increasing number of scholars in recent years. (Du et al., 2021; Li and Lin, 2017; Munisamy and Arabi, 2015; Quintano et al., 2020; Rybaczewska-Błażejowska and Masternak-Janus, 2018).

Related research methods and thoughts were also adopted in the field of the construction industry. Iribarren et al. (2015) proposed a method for selecting building components in accordance with the environmental efficiency based on DEA and life cycle assessment. $\mathrm{Hu}$ et al. (2017) evaluated the $\mathrm{CO}_{2}$ emission performance of Australian construction industry on the basis of Malmquist-DEA approach and serial benchmark technology. Feng and Wang (2017) investigated the driving force leading to the changes of energy efficiency, and the causes of both energy saving potential and the lower energy efficiency of China's regional construction industry by adopting metafrontier DEA approach. Azman et al. (2019) offered meta-frontier DEA approach to analyze the total factor productivity of Malaysian construction companies, further examining the components of productivity growth and capturing the technological gaps of construction companies. $\mathrm{Li}$ et al. (2020) established 30 provinces' $\mathrm{CO}_{2}$ emission performance index of China's construction industry by employing a modified nonradial DEA approach. 
As reviewed above, the performance measurement of the construction industry has shifted to a total factor type from a single factor type, and to an ecological perspective that takes the environment into account from an economic perspective. However, there remain some gaps in the research of the construction industry and can be summarized as follows. First, existing studies mostly ignore the indicators that represent social welfare in the construction industry (Wang, 2014; Wang et al., 2019; Zhou, et al., 2019).

By comparing different versions of Assessment standard for green building (GB/T 50378-2006, 2016; GB/T 50378-2014, 2014; GB/T 50378-2019, 2019), it showed that the new evaluation standards incorporated more thoughts of social dimension that reflecting comfort and livability. This provides a basis for adding new social welfare indicator. Second, existing studies mainly focused on a single perspective of static performance or dynamic change in the construction industry, which failed to fully reflect the green development level and development potential. This hinders the comprehensive assessment of green development and the proposal of corresponding optimization strategies in the construction industry in different regions of China. Third, previous studies either paid attention on the energy and pollution performance that reflecting energy conservation and environmental protection or the green total factor performance assessment with particular concerns at the provincial level, but few studies discussed the contribution of individual factors to the green total factor performance from the decomposition perspective.

Based on these research gaps, the Global non-radial DEA approach was employed in this paper to construct a unified framework combining both static and dynamic 
indexes. The floor space under construction and the park green area were incorporated into the unified total factor framework as social welfare indicators of the construction industry, representing comfort of living space and livability of ecological environment respectively. On this basis, the green total factor performance, including the static performance and dynamic change, were evaluated in 30 provinces of China' construction industry over the period 2005-2018. It is more reasonable in reflecting the green development level and potential of China's construction industry. Furthermore, by decomposing performance indexes, it can not only clarify the driving factors of green development, but also explore the reasons for the disparities among different regions, which is conducive to formulate more targeted policies to improve green performance of China's construction industry.

\section{Methodology}

\subsection{Global environmental production technology}

Assume that there are $j$ provinces assessed regarded as DMUs and $t$ periods in a production process. Each DMU employs $m$ inputs $X_{m}^{t}=\left(X_{1}^{t}, \ldots, X_{m}^{t}\right)^{\prime} \in R_{+}^{m}$, to produce $n \quad$ desirable outputs $\quad Y_{n}^{t}=\left(Y_{1}^{t}, \ldots, Y_{n}^{t}\right)^{\prime} \in R_{+}^{n} \quad$ and $\quad q \quad$ undesirable outputs $B_{q}^{t}=\left(B_{1}^{t}, \ldots, B_{q}^{t}\right)^{\prime} \in R_{+}^{q}$ in period $t$. The corresponding production technology set can be generally described as:

$$
P=\{(X, Y, B): X \text { can produce }(Y, B)\}
$$

In accordance with the research of Färe and Primont (1995), the set $P$ is convex, closed and bounded. When joint-production with multiple inputs and outputs are mentioned, three extra assumptions should be added (Färe et al., 1989): 
(1) If $(X, Y, B) \in P, X^{\prime}>X, Y^{\prime}<Y$, then $\quad\left(X^{\prime}, Y, B\right) \in P \quad$ and $\quad\left(X, Y^{\prime}, B\right) \in P$. Strongly disposability of inputs and desirable outputs states that the excessive inputs and desirable outputs can be disposed without any cost.

(2) If $(X, Y, B) \in P, B=0$, then $Y=0$. Null-jointness of desirable outputs and undesirable outputs states that undesirable outputs are unavoidable in production activities.

(3) If $(X, Y, B) \in P$, and $\alpha \in[0,1]$, then $(X, \alpha Y, \alpha B) \in P$. Weak disposability of desirable and undesirable outputs states that the reduction of undesirable outputs in production activities is not free.

When the Null-jointness and the weak disposability assumptions holds, $P$ is regard as the environmental production technology. The environmental production technology with constant returns to scale in period $t$ is identified as:

$$
P_{C R S}^{t}=\left\{(X, Y, B): \sum_{j=1}^{J} z_{j}^{t} X_{j m}^{t} \leqslant X_{m} ; \sum_{j=1}^{J} z_{j}^{t} Y_{j n}^{t} \geqslant Y_{n} ; \sum_{j=1}^{J} z_{j}^{t} B_{j q}^{t}=B_{q} ; z_{j}^{t} \geqslant 0, \forall j, m, n, q\right\}
$$

where, $z_{j}^{t}(j=1,2, \ldots, J ; t=1,2, \ldots, T)$ denotes the intensity variable of the $j$ th DMU in period $t$, and $\left(X_{j m}^{t}, Y_{j n}^{t}, B_{j q}^{t}\right)$ denotes the $m$ th inputs, the $n$th desirable outputs and the $q$ th undesirable outputs of the $j$ th DMU in period $t$.

Considering the limitations of environmental production technology in a single period, such as instability in estimating performance and inability to directly compare the performance of each DMU across periods, the global environmental production technology is adopted in this paper, which is mathematically expressed as follows (Wang et al., 2017): 


$$
P_{C R S}^{G}=\left\{\begin{array}{l|l}
(X, Y, B) & \begin{array}{l}
\sum_{t=1}^{T} \sum_{j=1}^{J} z_{j}^{t} X_{j m}^{t} \leqslant X_{m} ; \sum_{t=1}^{T} \sum_{j=1}^{J} z_{j}^{t} Y_{j n}^{t} \geqslant Y_{n} ; \\
\sum_{t=1}^{T} \sum_{j=1}^{J} z_{j}^{t} B_{j q}^{t}=B_{q} ; z_{j}^{t} \geqslant 0, \forall j, m, n, q, t
\end{array}
\end{array}\right\}
$$

\subsection{Global non-radial directional distance function}

The conventional directional distance function (DDF) may overestimate the efficiency of assessed DMUs when non-zero slacks exist (Fukuyama and Weber, 2009, 2010). Therefore, a non-radial directional distance function (NDDF) method proposed by Zhou et al. (2012), is employed in this paper to identify slacks of inputs, desirable outputs and by-products automatically. The NDDF with global environmental production technology (GNDDF) is defined as:

$$
N \vec{D}^{G}(X, Y, B ; g)=\sup \left\{\omega^{T} \beta:((X, Y, B)+\operatorname{diag}(\beta) \times g) \in P\right\}
$$

where $\omega=\left(\omega_{X}, \omega_{Y}, \omega_{B}\right)^{T}$ is a normalized vector, representing the weights allocated to each variable; $\beta=\left(\beta_{X}, \beta_{Y}, \beta_{B}\right)^{T} \geqslant 0$ is the vector that measure the maximum scaling possibility of the reduction of inputs and by-products and expansion of the desirable output; $\operatorname{diag}(\beta)$ represents a diagonal matrix with $\beta ; g=\left(g_{X}, g_{Y}, g_{B}\right)^{T}$ represents the direction vector determining the orientation in which each variable is scaled.

It should be noted that the directional vector $g$ and the weight vector $\omega$ can be adopted differently for different policy objectives. In this paper, the province applied energy (E), labor (L), and capital (K) to produce desirable outputs namely gross output value $(\mathrm{O})$, floor space under construction $(\mathrm{F})$, park green area $(\mathrm{P})$, and undesirable output $\mathrm{CO}_{2}$ emissions (C). By recognizing that savings in inputs, desirable outputs growth, and $\mathrm{CO}_{2}$ reduction are equally important (Lin and Du, 2015; Wang et al., 2013), 
combined with the variables selected, the directional vector is set as $(-E,-L,-K, O, F, P,-C)$ and the normalized vector is set as $(1 / 9,1 / 9,1 / 9,1 / 6,1 / 12,1 / 12,1 / 3)$

Subsequently, the GNDDF value is obtained by the following linear programming solution:

$$
\begin{array}{ll} 
& N \vec{D}^{G}\left(E^{t}, L^{t}, K^{t}, G^{t}, F^{t}, P^{t}, C^{t}\right)=\operatorname{Max} \omega_{E} \beta_{E}^{G t}+\omega_{L} \beta_{L}^{G t}+\omega_{K} \beta_{K}^{G t}+\omega_{O} \beta_{O}^{G t}+\omega_{F} \beta_{F}^{G t}+\omega_{P} \beta_{P}^{G t}+\omega_{C} \beta_{C}^{G t} \\
\text { s. } t . & \sum_{j=1}^{J} \sum_{t=1}^{T} z_{j}^{t} E_{j}^{t} \leqslant\left(1-\beta_{E}^{G t}\right) E_{j}^{t} ; \sum_{j=1}^{J} \sum_{t=1}^{T} z_{j}^{t} L_{j}^{t} \leqslant\left(1-\beta_{L}^{G t}\right) L_{j}^{t} ; \\
& \sum_{j=1}^{J} \sum_{t=1}^{T} z_{j}^{t} K_{j}^{t} \leqslant\left(1-\beta_{K}^{G t}\right) K_{j}^{t} ; \sum_{j=1}^{J} \sum_{t=1}^{T} z_{j}^{t} O_{j}^{t} \geqslant\left(1+\beta_{Y}^{G t}\right) O_{j}^{t} ; \\
& \sum_{j=1}^{J} \sum_{t=1}^{T} z_{j}^{t} F_{j}^{t} \geqslant\left(1+\beta_{F}^{G t}\right) F_{j}^{t} ; \sum_{j=1}^{J} \sum_{t=1}^{T} z_{j}^{t} P_{j}^{t} \geqslant\left(1+\beta_{P}^{G t}\right) P_{j}^{t} ; \\
& \quad \sum_{j=1}^{J} \sum_{t=1}^{T} z_{j}^{t} C_{j}^{t}=\left(1-\beta_{C}^{G t}\right) C_{j}^{t} ; \\
z_{j}^{t} \geqslant 0 ; j=1,2, \cdots, J ; t=1,2, \cdots, T ; \beta_{E}^{G t} \geqslant 0, \beta_{L}^{G t} \geqslant 0, \beta_{K}^{G t} \geqslant 0, \beta_{O}^{G t} \geqslant 0, \beta_{F}^{G t} \geqslant 0, \beta_{P}^{G t} \geqslant 0, \beta_{C}^{G t} \geqslant 0
\end{array}
$$

Similarly, the GNDDF of $t+1$ period, and the NDDF of $t$ and $t+1$ period can be established. Then, four kinds of distance function values can be estimated.

\subsection{Green Total factor Performance Index}

\subsubsection{Green total factor efficiency indicator (GEI)}

The energy efficiency indicator was initially defined by Zhou et al. (2012), as the ratio of actual energy efficiency to potential energy efficiency, and carbon performance indicator as the ratio of potential carbon intensity to actual carbon intensity. On this basis, Zhang et al. (2014) considered the efficiency values of all inputs and the $\mathrm{CO}_{2}$ emission efficiency to establish the total factor efficiency indicator. Suppose that $\beta_{j}=\left(\beta_{j E}^{*}, \beta_{j L}^{*}, \beta_{j K}^{*}, \beta_{j O}^{*}, \beta_{j F}^{*}, \beta_{j P}^{*}, \beta_{j C}^{*}\right)^{T}$ is the optimal solution to Eq. (5), the input efficiency indicators and $\mathrm{CO}_{2}$ emission efficiency indicator can be described as follows: 


$$
\begin{aligned}
X E I_{j} & =\frac{Y / X}{\left(Y+\beta_{Y}^{*} Y\right) /\left(X-\beta_{X}^{*} X\right)} \\
& =\frac{1-\beta_{j X}^{*}}{\frac{1}{3}\left(\left(1+\beta_{j O}^{*}\right)+\left(1+\beta_{j F}^{*}\right)+\left(1+\beta_{j P}^{*}\right)\right)} \\
& =\frac{1-\beta_{j X}^{*}}{1+\frac{1}{3}\left(\beta_{j O}^{*}+\beta_{j F}^{*}+\beta_{j P}^{*}\right)}, j=1,2, \cdots, J ; X=E, L, K . \\
C E I_{j} & =\frac{\left(C-\beta_{C}^{*} C\right) /\left(Y+\beta_{Y}^{*} Y\right)}{C / Y}=\frac{1-\beta_{j C}^{*}}{1+\frac{1}{3}\left(\beta_{j O}^{*}+\beta_{j F}^{*}+\beta_{j P}^{*}\right)}, j=1,2, \cdots, J
\end{aligned}
$$
indicator as shown in Eq. (7). This can not only estimate the green development level of China's construction industry, but also clarify its components.

$$
\begin{aligned}
G E I_{j} & =\frac{1}{4}\left(E E I_{j}+L E I_{j}+K E I_{j}+C E I_{j}\right) \\
& =\frac{1}{4}\left(\frac{1-\beta_{j E}^{*}}{1+\beta_{j Y}^{*}}+\frac{1-\beta_{j L}^{*}}{1+\beta_{j Y}^{*}}+\frac{1-\beta_{j K}^{*}}{1+\beta_{j Y}^{*}}+\frac{1-\beta_{j C}^{*}}{1+\beta_{j Y}^{*}}\right) \\
& =\frac{1-\frac{1}{4}\left(\beta_{j E}^{*}+\beta_{j L}^{*}+\beta_{j K}^{*}+\beta_{j C}^{*}\right)}{1+\frac{1}{3}\left(\beta_{j O}^{*}+\beta_{j F}^{*}+\beta_{j P}^{*}\right)}, j=1, \ldots, J
\end{aligned}
$$

\subsubsection{Green total-factor productivity indicator (GPI)}

Zhang and Choi (2013) defined Malmquist- $\mathrm{CO}_{2}$ performance indicator and measured total factor $\mathrm{CO}_{2}$ productivity. Combined with GNDDF, this paper establishes the dynamic productivity indicator of each factor, and then decomposed it into Technical Efficiency Change (EC) and Technological Change (TC) according to the decomposition of the Global Malmquist-Luenberger index (Oh, 2010)

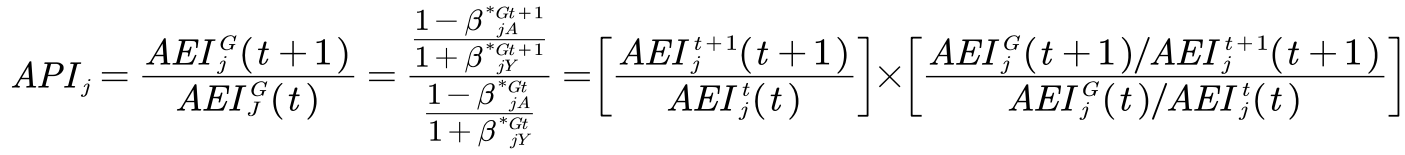

$$
\begin{aligned}
& =E C_{j A} \times T C_{j A}, \quad A=E, L, K, C
\end{aligned}
$$


Logarithm on both sides of each factor's productivity indicator is taken to get the approximate value of its growth rate. The approximate growth rate of the green total factor productivity indicator (GPI) can be defined as the arithmetic average of the sum of each factor's growth rate to estimate the green development potential of China's construction industry as shown in Eq. (9).

$$
\begin{aligned}
G P I_{j}= & \frac{1}{4}\left(\ln E P I_{j}+\ln L P I_{j}+\ln K P I_{j}+\ln C P I_{j}\right) \\
= & \frac{1}{4}\left(\ln E C_{j E}+\ln E C_{j L}+\ln E C_{j K}+\ln E C_{j C}\right) \\
& +\frac{1}{4}\left(\ln T C_{j E}+\ln T C_{j L}+\ln T C_{j K}+\ln T C_{j C}\right), \quad j=1, \ldots, J
\end{aligned}
$$

\section{Results and discussion}

\subsection{Data source and variable definitions}

In consideration of the validity and availability of the data, 30 provinces' construction industry in China are used to evaluate the green total factor performance during 2005-2018, except in Tibet, Hong Kong, Macao, and Taiwan. This paper adopts energy consumption, labor and capital (capital is expressed as the total assets of China's construction industry) as inputs and gross output value, floor space under construction, park green area as desirable outputs. The undesirable output is $\mathrm{CO}_{2}$ emissions. Almost all data for labor, capital, gross output value and floor space under construction are obtained from China Construction Statistical Yearbook (2006-2019). Data on park green area come from China Urban Construction Statistical Yearbook (2006-2019). To eliminate the effect of inflation, the GDP deflator of the secondary industry is used to convert capital and total output value into constant prices in 2005. 
Data pertaining to energy consumption are collected from the China Energy

Statistical Yearbook (2006-2019). 17 kinds of fossil fuels are selects and converted into standard coal equivalent by conversion coefficient. Indirect $\mathrm{CO}_{2}$ emissions from construction materials extremely exceeded the direct $\mathrm{CO}_{2}$ emissions from fossil energy consumption for the construction industry (Oh et al., 2017; Wei et al., 2013). According to Zhang and Liu (2013), CO2 emissions are composed of direct and indirect emissions. Total $\mathrm{CO}_{2}$ emissions can be computed according to IPCC as follows:

$$
C O_{2}=\sum_{i=1}^{17}\left(E C_{i} \times N C V_{i} \times C C_{i} \times C O_{i} \times \frac{44}{12}\right)+\sum_{j=1}^{5} F_{j} \times \xi_{j} \times\left(1-\eta_{j}\right)
$$

For $i$ th energy, where $E C_{i}, N C V_{i}, C C_{i}, C O_{i}$ represent total energy consumption, net caloric value, carbon content and the carbon oxidation rate respectively. Because the relevant emission factors are updated, values of these parameters are suggested by Shan et al. (2018) as shown in Table 1. As for building material $j$ th (including steel, wood, cement, glass and aluminum), where $F_{j}, \xi_{j}, \eta_{j}$ respectively denote material consumption, carbon emission coefficients and recycling coefficients, whose values are obtained from Sun (2016) as shown in Table 2.

Variable definition and descriptive statistics of data are listed in Table 3. The geographical classification of three regions is shown in Table 4.

\subsection{Green total factor efficiency of China's construction industry}

In this section, green total factor efficiency indicator (GEI) and its decompositions including energy efficiency indicator (EEI), labor efficiency indicator (LEI), capital efficiency indicator (KEI) and $\mathrm{CO}_{2}$ emission efficiency indicator (CEI) are analyzed from a static perspective. 


\subsubsection{Analysis of GEI at the national level}

As seen from Fig. 1, the GEI generally kept an upward trend, rising from 0.4858 in 2005 to 0.6662 in 2018 . The average GEI within the sample period was only 0.6023 , indicating that GEI of the 30 provinces could achieve an $39.8 \%$ increase relative to the production technology frontier on average. This implies that the green development level of China's construction industry still stays at a low level although some achievements have been made in transforming the development model and increasing production capacity.

As mentioned above, EEI, LEI, KEI and CEI together contributed to GEI. Among them, KEI and LEI had greater contribution to GEI, and their average efficiencies were 0.1929 and 0.1806 respectively, accounting for $32.34 \%$ and $30.00 \%$ of GEI. By contrast, EEI and CEI contributed little to GEI, with efficiencies of 0.1010 and 0.1279 , accounting for about $16.38 \%$ and $21.30 \%$ of GEI respectively. It showed that GEI mainly depended on the efficiency of traditional factors, KEI and LEI. This implies that China's construction industry is characterized with extensive economic growth mode, showing an urgent need for improvement in terms of transformation of economic development mode, energy conservation and environmental protection.

During the sample period, the efficiencies of all factors improved to different extent and the gap among them showed a narrowing trend as shown in Fig. 2. The EEI was always lower than the efficiency indicators of other factors, but it had the most obvious improvement and tended to catch up with CEI. The corresponding contribution of EEI to GEI grew significantly from $10.98 \%$ in 2005 to $19.46 \%$ in 2018 . By contrast, 
the KEI barely changed, with the corresponding contribution of KEI to GEI falling from $36.4 \%$ to $29.08 \%$. Besides, LEI and CEI also showed an upward trend to some extent, and their corresponding contribution to GEI were slightly increased and decreased respectively based on the calculated values in 2005 .

The above analysis showed that the lower EEI was the main reason for the inefficiency of GEI. It is essential to formulate compulsory energy consumption policies, supplemented by economic incentives like subsidies to the improvement of the energy efficiency. Some measures should also be taken for construction enterprises to improve construction energy efficiency by focusing on the use of energy-saving materials, improving the usage rates of machinery, and scientifically arranging construction process. Besides, the improvement in EEI was more obvious than that in CEI. One reason is that energy consumption and $\mathrm{CO} 2$ emissions have different characteristics. Reducing energy consumption can save costs, thereby improving the enthusiasm of enterprises to save energy. On the contrary, $\mathrm{CO} 2$ emissions have high negative externalities, which weakens the incentive of enterprises to control pollution to some extent. Another reason is that the energy utilization structure is unreasonable. China's construction industry is far more dependent on fossil energy than new energy, causing serious air pollution. Transformation and upgrading of energy can ensure that equal amount of energy consumption produces less $\mathrm{CO}_{2}$. Therefore, the optimization of the energy structure and guidance for upgrading energy types will be an effective way to reduce pollution emissions and improve $\mathrm{CO}_{2}$ emission efficiency. In addition, the KEI accounted for the largest proportion of the GEI, but the improvement of KEI was 
not obvious, indicating that a more reasonable investment should be considered and the inputs of various factors need to be coordinated to improve KEI rather than a large amount of capital invested simply.

\subsubsection{Regional discrepancy of GEI}

The distribution of regional GEI were imbalanced as shown in Fig. 3. From 2005 to 2018, the overall performance of GEI decreased from the east to the west. The eastern region had the highest GEI with an average value of 0.6976 , while those of the central and the western regions were only 0.5830 and 0.5211 . The GEI of these three regions all increased over time, and the eastern region was the one where GEI rose even more significantly. This could be caused by many factors, such as a more solid economic foundation, a higher degree of openness, and a more mature construction market in the eastern region.

As far as the decomposition of GEI were concerned, the average values of all factors' efficiency indicators during 2005 to 2018 in the eastern region were almost in a leading position as shown in Fig. 4. Obviously, the allocation of the production factors in the eastern region tended to be more reasonable and effective. During the sample period, LEI in three regions maintained persistent and steady growth with little difference, while KEI grew weakly and KEI in the central region even showed a decreasing trend. In terms of EEI and CEI, their values in the eastern region have made significant leaps since around 2010, and the gap with those in central and the western regions has further widened since then. Actually, the EEI in the central and the western regions also increased, and the EEI in the western region had caught up with that in the 
central region around 2015. On the contrary, the CEI in the central and the western regions produced modestly changes. It should be noted that the sources of the GEI were varied among three regions. In the eastern region, the contribution of EEI to GEI, and CEI to GEI were higher than those in the central and the western regions, while the contributions of LEI to GEI, and KEI to GEI were lower than those in the central and the western regions. Specifically, the contribution of EEI to GEI, and CEI to GEI were $20.23 \%$ and $22.08 \%$ respectively in the eastern region, while the corresponding contribution of these two indicators were $15.72 \%$ and $20.75 \%$ in the central region, $12.99 \%$ and $20.48 \%$ in the western region. The contribution of LEI to GEI, and KEI to GEI were $28.15 \%$ and $29.55 \%$ respectively in the eastern regions, while the corresponding contribution of these two indicators were $30.27 \%$ and $33.26 \%$ in the central region, $32.21 \%$ and $34.32 \%$ in the western region.

The above analysis indicated that the lower EEI and the lower CEI were the main reasons for the inefficiency of GEI in underdeveloped regions. With the proposal of packages of policies related to energy conservation and emission reduction in the end of the Tenth Five-Year Plan, the work of energy conservation and environmental protection of China's construction has been entered into a stage of comprehensive development. Obviously, the central and the western regions still need to improve the creation of the soft environment for green development of the construction industry, and learn economic development mode from the eastern region. In addition to improving the efficiencies of traditional capital and labor inputs, energy conservation and environmental protection should be further strengthened in underdeveloped regions 
to reduce the gap with developed regions.

\subsection{Green total factor productivity of China's construction industry}

After evaluation of GEI, green total factor productivity indicator (GPI) and its decomposition were measured in this section from a dynamic perspective.

\subsubsection{Analysis of GPI at the national level}

GPI and its decomposition were shown in Table 5. During the sample period, the annual growth rate in GPI was 0.0322 , with TC and EC changing 0.0331 and -0.0009 respectively. It indicated that technological progress was the determinant of GPI growth, and the decline in technical efficiency was its obstructive factor. For decades, a huge $R \& D$ inputs have been invested in the construction industry, leading to a sharp increase in the number of patents granted and new green buildings, which has significantly improved the technology of China's construction industry. However, the technical efficiency improvement should not be ignored as a cost-effective way.

By decomposing GPI further, 0.0222 was rooted in EPI and 0.0067 was sourced from LPI, which were the main factors to the GPI growth. By contrast, KPI and CPI changed by 0.0018 and 0.0015 respectively, the sum of which accounted for only about $10 \%$ of GPI. It indicated that the $\mathrm{CO}_{2}$ emission and the capital efficiencies did not significantly improve during the sample period. For EC, EC of the energy contributed the most positive effects, while $\mathrm{EC}$ of the $\mathrm{CO}_{2}$ emissions exerted the most negative impact. In order to reverse the deterioration of $\mathrm{EC}$ of the $\mathrm{CO}_{2}$ emissions, it is necessary for construction enterprises to adopt more effective management for enhanced $\mathrm{CO}_{2}$ emission reduction. The improvement of TC was driven by the technological progress 
of all factors, indicating that it made a great technological progress in energy conservation and energy efficiency, but very little progress in capital.

To analyze the changes in GPI more clearly, Fig. 5 reflects the dynamic evolution of GPI and its decomposition during 2005-2018. On the whole, except for the three periods of 2007-2008, 2014-2015, and 2016-2017, GPI kept positive increasing in the remaining years. TC showed downward trends in 2014-2015, 2015-2016, 2016-2017, and there were five periods when EC declined. Among them, GPI performed the worst in 2014-2015, not only because it had the largest decline, but also because all factors had negative effects on it.

The trend of GPI was in agreement with the study results of Zhang et al. (2020). During the period 2014-2015, GPI experienced a sharp decline, followed by fluctuations in rising and falling trends. Slower growth of the desired outputs was the main reason for the fall of GPI over the period. The annual growth rate in gross output value in 2015 was only $2.6 \%$, which was significantly lower than that of $10.2 \%$ in 2014 . The floor space under construction in 2015 decreased by $0.58 \%$, while in 2014 it increased by $10.4 \%$. Besides, the growth rate of the park green area also slowed down. These changes lead to the shift from the technological frontier of the same period to the global technological frontier in the direction of less expected outputs, causing the decline of GPI. In addition, the weak investment growth under the new normal also had a negative impact on GPI, which was heavily dependent on inputs growth. Except for the period of 2014-2015, almost all the driving force for the GPI growth depended on the effects of inputs, while CPI only produced a weak promotion or even inhibition. 
This once again demonstrated the importance of the Chinese government's efforts to strengthen guidance on $\mathrm{CO}_{2}$ emission reduction.

\subsubsection{Regional discrepancy of GPI}

Some disparities existed in GPI among different regions as shown in Table 5. The GPI in the eastern region was 0.0388 , higher than those in the central and the western regions at 0.0214 and 0.0335 , respectively. In these three regions, TC was always much higher than EC, indicating that technological progress made the major contribution to the GPI growth. Actually, the central region was the only one where EC had a negative effect to GPI. The eastern region took a lead in R\&D of technology, while the western region was more advanced in technology diffusion.

The reasons for GPI growth in three regions were quite different. In the eastern region, the positive effects of all factors were contributors to the GPI growth. In the central region, the EPI and the LPI were the two main drivers to the increase in GPI, while the KPI and the CPI were the dominant factors behind the decrease in GPI. The CPI was the only obstructive factor to GPI in the western region. For EC, the EC of $\mathrm{CO}_{2}$ emissions was the powerful inhibitor in all three regions. In addition, the EC of energy was another obstructive factor in the central region, and the EC of capital also had a negative effect in the western region. In the three regions, almost TC of all factors effected to TC positively except for the TC of capital in the central region.

Fig. 6 showed the distribution of GPI, TC and EC in three regions. First, although the eastern region had the highest GPI, the internal provinces were quite divergent on GPI performance. It demonstrated that the "Matthew Effect" might exist, mainly 
because of the large differences in TC within the region. Second, though there was a gap with developed region in the increase in GPI, the GPI distribution in the western region was relatively concentrated, demonstrating that the green development in the construction industry was more balanced within the western region. Third, the central region showed the lowest GPI growth, and there were significant regional differences in $\mathrm{EC}$ and $\mathrm{TC}$ within the region, demonstrating that there existed a big gap in the ability of technology diffusion in different provinces of the central region.

\subsection{Selection of green development strategies in different provinces}

Evaluation of the green development level and development potential of each province can provide a reasonable and effective basis for formulating regional green development strategy. Using the median of GEI and GPI values $\left(\mathrm{GEI}_{\mathrm{m}}\right.$ and $\mathrm{GPI}_{\mathrm{m}}$ represent the median of GEI and GPI respectively) as the dividing point, a provincial classification method was proposed in this study (see Fig. 7, Fig. 8). It can not only analyze the ranking of GEI or GPI of each province individually, but also consider them comprehensively, and thereby determine the key directions for future work.

As per the GEI ranking, the eastern region took the absolute lead, with eight provinces possessing higher GEI than $\mathrm{GEI}_{\mathrm{m}}$. By contrast, the western region generally lagged behind, with seven provinces possessing lower GEI than GEI $\mathrm{m}_{\mathrm{m}}$. The GEI of the central provinces were quite divergent, with Heilongjiang province ranking the first and Shanxi Province ranking the third last. For GPI ranking, the eastern region still performed well, with seven provinces possessing higher GPI than GPI $\mathrm{I}_{\mathrm{m}}$. Most western provinces ranked in the middle, but the performance was unsatisfactory in the central 
region, with six provinces possessing lower GPI than $\mathrm{GPI}_{\mathrm{m}}$.

From Fig. 8, Zhejiang and 10 other provinces were identified as type I provinces, which had high green development level with high development potential. This implied that the economic, environmental and social dimensions of the construction industry in these provinces could develop in coordination, which were worth learning from the neighboring provinces. The type II provinces had advantages in GEI but were weak in GPI growth. For such provinces, because they did not have the potential for green development, they were at risk of being overtaken by other provinces. Therefore, the local governments of type II provinces should focus on the improvement of GPI growth. Specifically, the optimization strategies for GPI growth in Hainan, Guangdong, Jiangxi, Jilin should focus on EC, and Heilongjiang should strengthen both EC and TC. Contrary to the type II provinces, the GEI of type III provinces was low, but the GPI grows rapidly. This was inseparable from the persistent efforts by the local authorities to reinforce governance effectively and innovate construction technology continuously. However, the weak effect of GEI indicated that avoiding unnecessary inputs and undesirable output is the key to improving GEI. Therefore, local governments should organize the input of various factors more rationally, and reinforce efforts in $\mathrm{CO}_{2}$ emission reduction. The type IV provinces were at the bottom both in GEI and GPI, $80 \%$ of which belonged to the central and the western regions. Such provinces were generally with low energy and $\mathrm{CO}_{2}$ emission efficiency, which was related to their poor management and technical recessions, and they were the objects that need to be focused on comprehensive rectification. The analysis showed that significant disparities existed among different 
regions in the green development level and development potential of China's construction industry, so it is essential to formulate regional green development strategies based on local realities.

\section{Conclusion and Policy Implications}

The improvement of green total factor performance in the construction industry is an inherent requirement of China's significant strategic decision to achieve carbon peak and neutrality goals. This paper adopted the Global non-radial DEA approach to make a deep analysis on the regional green performance of China's construction industry from static and dynamic perspectives. The findings are as follows:

(1) The lower GEI indicated that China's construction industry did not realize total factor coordination in the green development. Energy and $\mathrm{CO}_{2}$ emissions were much less efficient than capital and labor. The efficiencies of all factors increased, with the largest increase in energy efficiency. This implies that great progress has been made in intensive use of energy in the construction industry, but it still needs to be strengthened in terms of transformation of economic development mode, guidance for upgrading energy types, energy conservation and environmental protection.

(2) The GPI demonstrated an increasing trend, mainly driven by technological progress rather than technical efficiency improvement. In green development of China's construction industry, the technological innovation was superior to the management improvement. Specifically, the deterioration of technical efficiency was mainly caused by the negative effect of $\mathrm{CO}_{2}$ emissions. The 
negative externality of $\mathrm{CO}_{2}$ emissions could be the main reason why construction enterprises lack the motivation to improve management to reduce $\mathrm{CO}_{2}$ emissions and improve $\mathrm{CO}_{2}$ emission efficiency. In addition, KPI contributed least to GPI growth, indicating that the effect of capital allocation has not been effectively enhanced.

(3) Some disparities existed in green total factor performance among different regions. The eastern region took a leading position in terms of green development level and potential. Compared with the central region, the western region had greater potential for green development, although its green development level was relatively low. Notably, the eastern region was the only one where CPI had a positive effect on GPI growth due to its significant technological progress. $\mathrm{EC}$ of $\mathrm{CO}_{2}$ emissions among regions deteriorated to different extent. The results of classification implied that provinces belonging to different types need adopt different strategies based on local realities.

The above findings have a series of corresponding policy implications. First, to achieve breakthroughs in green development of China's construction industry, Structural $\mathrm{CO}_{2}$ reduction should be put in the first place. Specifically, it is necessary to focus on energy transformation and upgrading, such as replacing fossil energy with local new energy sources, strengthening the technology upgrading of building materials. It is also necessary for enterprises to organize the construction process reasonably to achieve the intensive use of energy. Second, governments should pay high attention on the management improvement in the construction industry, such as formulating 
mandatory carbon emission reduction targets and economic policies. The research on

503 the rationality and scientificity of capital allocation need to be explored to fully release

504 the potential of the capital utilization. Third, the government should strengthen inter-

505 regional and inter-provincial cooperation, especially establishing pair-assist

506 mechanisms for guiding advanced technology in energy conservation and $\mathrm{CO}_{2}$

507 reduction transferring from the eastern region to the central and the western regions, to

508 promote the coordinated development among regions and provinces.

509 
The authors gratefully acknowledge the financial support by the National Natural

Science Foundation of China (Grant No. 51976147) and the Outstanding Youth Science Fund of Shaanxi Province (Grant No. 2021JC-05).

\section{Author contribution}

JF Wang and Y Li conceptualized the framework of this study and revised the final version of the original manuscript. Y Li contributed to the data calculation, methodology, results analysis and manuscript writing. B Liu and HY Li assisted to collect the data and participated in the data calculation. YM Guo and XR Guo helped to revise the original manuscript, especially giving appropriate suggestions on the designing of figures.

\section{Funding} (Grant No. 2021JC-05).

The original data in this study are all from the statistical yearbook mentioned in this paper, and the calculation results generated or analyzed are included in this paper. 


\section{Declarations}

\section{$533 \quad$ Ethics approval}

$534 \quad$ Not applicable.

535

536 Consent to participate

537

Not applicable.

538

539

\section{Consent for publication}

540 All authors agreed with the content and all gave explicit consent to submit the

541 manuscript.

542

543 Competing Interests

$544 \quad$ The authors declare no competing interests.

545 


\section{References}

Ang, B.W., 1999. Is the energy intensity a less useful indicator than the carbon factor in the study of climate change? Energy Policy 27 (15), 943-946. https://doi.org/10.1016/S0301-4215(99)00084-1

Azadi, M., Jafarian, M., Farzipoor Saen, R., Mirhedayatian, S.M., 2015. A new fuzzy DEA model for evaluation of efficiency and effectiveness of suppliers in sustainable supply chain management context. Computers \& Operations Research 54, 274-285. https://doi.org/10.1016/j.cor.2014.03.002

Azman, M.A., Hon, C.K.H., Skitmore, M., Lee, B.L., Xia, B., 2019. A Meta-frontier method of decomposing long-term construction productivity components and technological gaps at the firm level: evidence from Malaysia. Construction $\begin{array}{lllll}\text { Management } \quad \text { and } & \text { Economics } & 37 & \text { (2), } & \text { 72-88. }\end{array}$ https://doi.org/10.1080/01446193.2018.1506139

CABEE, 2021. China Building Energy Consumption Annual Report 2020. Journal of BEE 49 (02):1-6. 10.3969/j.issn.2096-9422.2021.02.001

China Construction Statistical Yearbook., 2006-2019. China Statistics Press, Beijing. China Energy Statistical Yearbook., 2006-2019. China Statistics Press, Beijing.

China Urban Construction Statistical Yearbook., 2006-2019. China Statistics Press, Beijing.

Du, Q., Wu, J., Cai, C., Li, Y., Zhou, J., Yan, Y., 2021, Carbon mitigation by the construction industry in China: a perspective of efficiency and costs. Environmental Science and Pollution Research 28 (1), 314-325. https://doi.org/10.1007/s11356-02010412-Z

Ederer, N., 2015. Evaluating capital and operating cost efficiency of offshore wind farms: A DEA approach. Renewable and Sustainable Energy Reviews 42, 1034-1046. https://doi.org/10.1016/j.rser.2014.10.071

Färe, R., Grosskopf, S., Lovell, C., Pasurka, C., 1989. Multilateral productivity comparisons when some outputs are undesirable: a nonparametric approach. The Review of Economics and Statistics 71 (1), 90-98. https://doi.org/10.2307/1928055

Färe, R., Primont, D., 1995. Multi-Output Production and Duality: Theory and Applications. Kluwer Academic Publishers, Boston.

Feng, C., Wang, M., 2017. The economy-wide energy efficiency in China's regional $\begin{array}{llll}\text { building } \quad \text { industry. } & \text { Energy } & 141, & 1869-1879 .\end{array}$ https://doi.org/10.1016/j.energy.2017.11.114

Fukuyama, H., Weber, W.L., 2009. A directional slacks-based measure of technical inefficiency. Socio-Economic Planning Sciences 43 (4), 274-287. https://doi.org/10.1016/j.seps.2008.12.001

Fukuyama, H., Weber, W.L., 2010. A slacks-based inefficiency measure for a two-stage

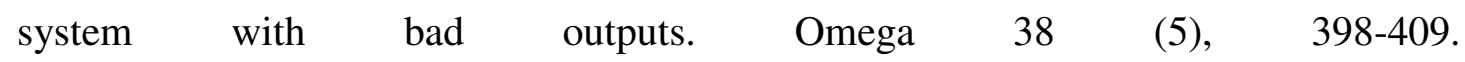
https://doi.org/10.1016/j.omega.2009.10.006

GB/T 50378-2006., 2006. Assessment standard for green building. Beijing: China Architecture and Building Press.

GB/T 50378-2014., 2014. Assessment standard for green building. Beijing: China 
Architecture and Building Press.

GB/T 50378-2019., 2019. Assessment standard for green building. Beijing: China Architecture and Building Press.

Halkos, G.E., Tzeremes, N.G., 2009. Exploring the existence of Kuznets curve in countries' environmental efficiency using DEA window analysis. Ecological Economics 68 (7), 2168-2176. https://doi.org/10.1016/j.ecolecon.2009.02.018

He, Q., Tan, S., Yin, C., Zhou, M., 2019. Collaborative optimization of rural residential land consolidation and urban construction land expansion: A case study of Huangpi in Wuhan, China. Computers, Environment and Urban Systems 74, 218-228. https://doi.org/10.1016/j.compenvurbsys.2018.11.005

Honma, S., Hu, J.L., 2013. Total-factor Energy Efficiency for Sectors in Japan. Energy Sources, Part B: Economics, Planning and Policy 8 (2), 130-136. https://doi.org/10.1080/15567240903289564

$\mathrm{Hu}$, J., Wang, S., 2006. Total-factor energy efficiency of regions in China. Energy Policy 34 (17), 3206-3217. https://doi.org/10.1016/j.enpol.2005.06.015

$\mathrm{Hu}$, X., Liu, C., 2016. Carbon productivity: a case study in the Australian construction industry. Journal of Cleaner Production 112 (Part 4), 2354-2362. https://doi.org/10.1016/j.jclepro.2015.10.042

Hu, X., Si, T., Liu, C., 2017. Total factor carbon emission performance measurement and development. Journal of Cleaner Production 142 (Part 4), 2804-2815. https://doi.org/10.1016/j.jclepro.2016.10.188

Iribarren, D., Marvuglia, A., Hild, P., Guiton, M., Popovici, E., Benetto, E., 2015. Life cycle assessment and data envelopment analysis approach for the selection of building components according to their environmental impact efficiency: a case study for external walls. Journal of Cleaner Production 87, 707-716. https://doi.org/10.1016/j.jclepro.2014.10.073

Li, J., Lin, B., 2017. Ecological total-factor energy efficiency of China's heavy and light industries: Which performs better? Renewable and Sustainable Energy Reviews 72, 8394. https://doi.org/10.1016/j.rser.2017.01.044

Li, W., Wang, W., Gao, H., Zhu, B., Gong, W., Liu, Y., Qin, Y., 2020. Evaluation of regional metafrontier total factor carbon emission performance in China's construction industry: Analysis based on modified non-radial directional distance function. Journal of Cleaner Production 256, 120425. https://doi.org/10.1016/j.jclepro.2020.120425 Lin, B., Du, K., 2015, Energy and CO2 emissions performance in China's regional economies: Do market-oriented reforms matter? Energy policy 78, 113-124. https://doi.org/10.1016/j.enpol.2014.12.025

MOHURD., 2021. Develop green construction methods and promote high-quality development of urban and rural construction. http://www.chinajsb.cn/html/202104/14/19426.html (accessed 13 May 2021).

Mukherjee, K., 2008a. Energy use efficiency in U.S. manufacturing: A nonparametric analysis. Energy Economics 30 (1), 76-96. https://doi.org/10.1016/j.eneco.2006.11.004 Mukherjee, K., 2008b. Energy use efficiency in the Indian manufacturing sector: An $\begin{array}{lllll}\text { interstate analysis. } & \text { Energy } & \text { (2), 6olicy } 36-672 .\end{array}$ https://doi.org/10.1016/j.enpol.2007.10.015 
Munisamy, S., Arabi, B., 2015. Eco-efficiency change in power plants: using a slacksbased measure for the meta-frontier Malmquist-Luenberger productivity index. Journal of Cleaner Production 105, 218-232. https://doi.org/10.1016/j.jclepro.2014.12.081

Oh, D., 2010. A global Malmquist-Luenberger productivity index. Journal of Production Analysis 34 (3), 183-197. https://doi.org/10.1007/s11123-010-0178-y Oh, B.K., Choi, S.W., Park, H.S., 2017. Influence of variations in $\mathrm{CO}_{2}$ emission data upon environmental impact of building construction. Journal of Cleaner Production 140 (Part 3), 1194-1203. https://doi.org/10.1016/j.jclepro.2016.10.041

Quintano, C., Mazzocchi, P., Rocca, A., 2020. Examining eco-efficiency in the port sector via non-radial data envelopment analysis and the response based procedure for detecting unit segments. Journal of Cleaner Production 259, 120979. https://doi.org/10.1016/j.jclepro.2020.120979

Rybaczewska-Błażejowska, M., Masternak-Janus, A., 2018. Eco-efficiency assessment of Polish regions: Joint application of life cycle assessment and data envelopment analysis. Journal of Cleaner Production 172, 1180-1192. https://doi.org/10.1016/j.jclepro.2017.10.204

Shan, Y., Guan, D., Zheng, H., Ou, J., Li, Y., Meng, J., Mi, Z., Liu, Z., Zhang, Q., 2018. China $\mathrm{CO}_{2}$ emission accounts 1997-2015. Scientific Data 5, 170201. https://doi.org/10.1038/sdata.2017.201

Sueyoshi, T., Goto, M., 2014. Photovoltaic power stations in Germany and the United States: A comparative study by data envelopment analysis. Energy Economics 42, 271288. https://doi.org/10.1016/j.eneco.2014.01.004

Sun, W., 2016. Statistical research on carbon intensity differences of regional construction industry. Taiyuan University of Technology.

Wang, H., Zhou, P., Zhou, D.Q., 2013. Scenario-based energy efficiency and productivity in China: A non-radial directional distance function analysis. Energy Economics 40, 795-803. https://doi.org/10.1016/j.eneco.2013.09.030

Wang, L., Long, R., Chen, H., Li, W., Yang, J., 2019. A review of studies on urban energy performance evaluation. Environmental Science and Pollution Research 26 (4), 3243-3261. https://doi.org/10.1007/s11356-018-3915-9

Wang, N., 2014. The role of the construction industry in China's sustainable urban development. Habitat International 44, 442-450. https://doi.org/10.1016/j.habitatint.2014.09.008

Wang, Z., He, W., Wang, B., 2017. Performance and reduction potential of energy and $\mathrm{CO}_{2}$ emissions among the APEC's members with considering the return to scale. Energy 138, 552-562. https://doi.org/10.1016/j.energy.2017.07.059

Wei, X., Lai, J., Zhang, J., 2013. Carbon-emission calculation of electromechanical energy consumption of different structures during the construction phase. Journal of Chongqing University (English Edition) 12 (2), 67-74. 10.11835/j.issn.1671$\underline{8224.2013 .02 .003}$

Zhang, J., Jin, W., Li, H., Peng, X., Xu, H., 2020. Measuring the Dynamic Green Total Factor Productivity of China's Construction Industry. Journal of Engineering Management 34 (01):1-6. 10.13991/j.cnki.jem.2020.01.001

Zhang, N., Choi, Y., 2013. Total-factor carbon emission performance of fossil fuel 
power plants in China: A metafrontier non-radial Malmquist index analysis. Energy Economics 40, 549-559. https://doi.org/10.1016/j.eneco.2013.08.012 Zhang, N., Kong, F., Choi, Y., Zhou, P., 2014. The effect of size-control policy on unified energy and carbon efficiency for Chinese fossil fuel power plants. Energy Policy 70, 193-200. https://doi.org/10.1016/j.enpol.2014.03.031

Zhang, X., Cheng, X., Yuan, J., Gao, X., 2011, Total-factor energy efficiency in developing countries. Energy Policy $39 \quad$ (2), 644-650. https://doi.org/10.1016/j.enpol.2010.10.037

Zhang, Y., Liu, Z., Zhang, H., Tan, T., 2014. The impact of economic growth, industrial structure and urbanization on carbon emission intensity in China. Natural Hazards 73 (2), 579-595. https://doi.org/10.1007/s11069-014-1091-X

Zhang, Z., Liu, R., 2013. Carbon emissions in the construction sector based on inputoutput analyses. Journal of Tsinghua University (Science and Technology) 53 (01), 5357. 10.16511/j.cnki.qhdxxb.2013.01.007

Zhou, P., Ang, B.W., Wang, H., 2012. Energy and $\mathrm{CO}_{2}$ emission performance in electricity generation: A non-radial directional distance function approach. European $\begin{array}{lllll}\text { Journal of } & \text { Operational } & \text { 625-635. }\end{array}$ https://doi.org/10.1016/j.ejor.2012.04.022 Zhou, S., Wang, Y., Gao, Y., Luo, W., 2019. Research on the development and challenge of green sustainable construction project under comprehensively building a well-off society. Think Tank: Theory and Practice 4 (06):92-102. 10.19318/j.cnki.issn.2096-1634.2019.06.12

Zhu, X., Zhang, P., Wei, Y., Li, Y., Zhao, H., 2019. Measuring the efficiency and driving factors of urban land use based on the DEA method and the PLS-SEM modelA case study of 35 large and medium-sized cities in China. Sustainable Cities and Society 50, 101646. https://doi.org/10.1016/j.scs.2019.101646 
705 Table 1 The carbon emission coefficients of fuels

706 Table 2 The carbon emission and recycling coefficients of main building materials

707 Table 3 Variable definition and descriptive statistics of data

708 Table 4 Regions in mainland China

709 Table 5 GPI and its decompositions during 2005-2018

$710 \quad$ Figure captions

711 Fig. 1 GEI and its decompositions during 2005-2018

712 Fig. 2 Average values of factors and their contributions to GEI during 2005-2018

713 Fig. 3 GEI in three regions: 2005-2018

714 Fig. 4 Sources of GEI in three regions: 2005-2018

715 Fig. 5 Dynamic evolution of GPI and its decompositions: 2005-2018

716 Fig. 6 GPI, EC and TC in three regions

717 Fig. 7 Green total factor performance of 30 provinces in China

718 Fig. 8 Province division for green total factor performance of China's construction industry 
Table 1 The carbon emission coefficients of fuels

\begin{tabular}{cccc}
\hline $\begin{array}{c}\text { Fuel } \\
\text { type }\end{array}$ & $\begin{array}{c}\mathrm{NCV}_{\mathrm{i}} \\
\mathrm{PJ} / 10^{4} \text { tonnes, } 10^{8} \mathrm{~m}^{3}\end{array}$ & $\begin{array}{c}\mathrm{CC}_{\mathrm{i}} \\
\text { tonneC/TJ }\end{array}$ & $\mathrm{CO}_{\mathrm{i}}$ \\
\hline Raw Coal & 0.21 & 26.32 & $83 \%$ \\
Cleaned Coal & 0.26 & 26.32 & $83 \%$ \\
Other Washed & 0.15 & 26.32 & $83 \%$ \\
Coal & 0.18 & 26.32 & $83 \%$ \\
Briquettes & 0.28 & 31.38 & $89 \%$ \\
Coke & 1.61 & 21.49 & $91 \%$ \\
Coke Oven Gas & 0.83 & 21.49 & $91 \%$ \\
Other Gas & 0.28 & 27.45 & $89 \%$ \\
Other Coking & 0.43 & 20.08 & $96 \%$ \\
Products & 0.44 & 18.9 & $96 \%$ \\
Crude Oil & 0.44 & 19.6 & $96 \%$ \\
Gasoline & 0.43 & 20.2 & $96 \%$ \\
Kerosene & 0.43 & 21.1 & $96 \%$ \\
Diesel Oil & & 20 & $97 \%$ \\
Fuel Oil & 0.47 & 20.2 & $97 \%$ \\
Liquefied & 0.43 & 17.2 & $96 \%$ \\
petroleum gas & & 15.32 & $98 \%$ \\
Refinery Gas & 0.51 & & \\
Other Petroleum & 3.89 & & \\
Products & & & \\
Natural Gas & & & \\
\hline
\end{tabular}

Table 2 The carbon emission and recycling coefficients of main building materials

\begin{tabular}{cccccc}
\hline $\begin{array}{c}\text { Building material } \\
\text { type }\end{array}$ & Cement & Glass & Steel & Aluminum & Wood \\
\hline$\xi_{j}$ & 0.8150 & 0.9655 & 1.7890 & 2.6000 & -842.8000 \\
& $\mathrm{~kg} / \mathrm{kg}$ & $\mathrm{kg} / \mathrm{kg}$ & $\mathrm{kg} / \mathrm{kg}$ & $\mathrm{kg} / \mathrm{kg}$ & $\mathrm{kg} / \mathrm{m}^{3}$ \\
$\eta_{j}$ & $/$ & 0.70 & 0.80 & 0.85 & 0.20 \\
\hline
\end{tabular}


Table 3 Variable definition and descriptive statistics of data

\begin{tabular}{|c|c|c|c|c|c|c|}
\hline Variable & Definition & Unit & Min. & Max. & Mean. & Std.Dev. \\
\hline \multicolumn{7}{|c|}{ Desirable outputs } \\
\hline $\mathrm{y}_{1}$ & $\begin{array}{c}\text { Gross output } \\
\text { value }\end{array}$ & $\begin{array}{l}10^{9} \text { yuan in } \\
2005 \text { prices }\end{array}$ & 5.97 & 1877.94 & 297.43 & 320.73 \\
\hline $\mathrm{y}_{2}$ & $\begin{array}{c}\text { Floor space } \\
\text { under } \\
\text { construction }\end{array}$ & $10^{6} \mathrm{~m}^{2}$ & 3.47 & 2491.77 & 298.04 & 400.88 \\
\hline $\mathrm{y} 3$ & Park green area & $10^{2} \mathrm{hm}^{2}$ & 5.62 & 1058.10 & 165.24 & 151.49 \\
\hline \multicolumn{7}{|c|}{ Undesirable output } \\
\hline $\begin{array}{c}\mathrm{y} 4 \\
\text { Inputs }\end{array}$ & $\mathrm{CO}_{2}$ emissions & $10^{6}$ tons & 0.88 & 944.54 & 54.99 & 84.15 \\
\hline $\mathrm{X}_{1}$ & $\begin{array}{c}\text { Energy } \\
\text { consumption }\end{array}$ & $\begin{array}{c}10^{4} \text { tons of } \\
\text { standard } \\
\text { coal } \\
\text { equivalent }\end{array}$ & 2.27 & 555.53 & 94.87 & 78.45 \\
\hline $\mathrm{x}_{2}$ & Labor & $10^{4}$ persons & 5.48 & 811.03 & 138.89 & 155.49 \\
\hline $\mathrm{X}_{3}$ & Capital & $\begin{array}{l}10^{9} \text { yuan in } \\
2005 \text { prices }\end{array}$ & 3.76 & 1651.40 & 262.59 & 265.46 \\
\hline
\end{tabular}

Table 4 Regions in mainland China

\begin{tabular}{cl}
\hline Region & \multicolumn{1}{c}{ Provinces, autonomous regions, and municipalities } \\
\hline \multirow{2}{*}{ East group } & Liaoning, Hebei, Beijing, Tianjin, Shandong, Zhejiang, Jiangsu, Shanghai, \\
Fujian, Guangdong, Hainan \\
Central group & $\begin{array}{l}\text { Heilongjiang, Jilin, Henan, Jiangxi, Shanxi, Anhui, Hubei, Hunan } \\
\text { West group } \\
\text { Inner Mongolia, Xinjiang, Qinghai, Gansu, Ningxia, Shaanxi, Guizhou, } \\
\text { Chongqing, Yunnan, Sichuan, Guangxi }\end{array}$ \\
\hline
\end{tabular}


Table 5 GPI and its decompositions during 2005-2018

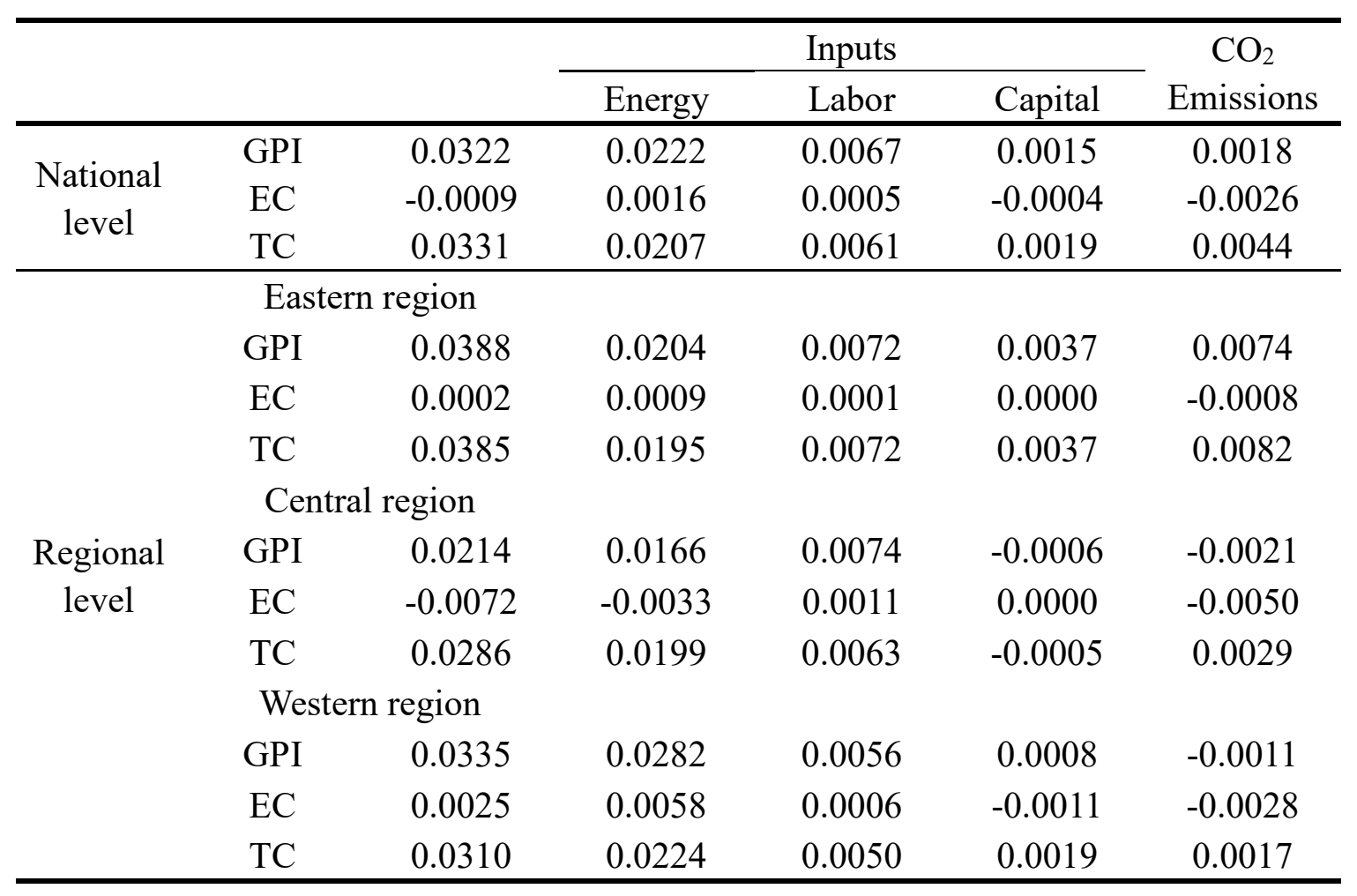




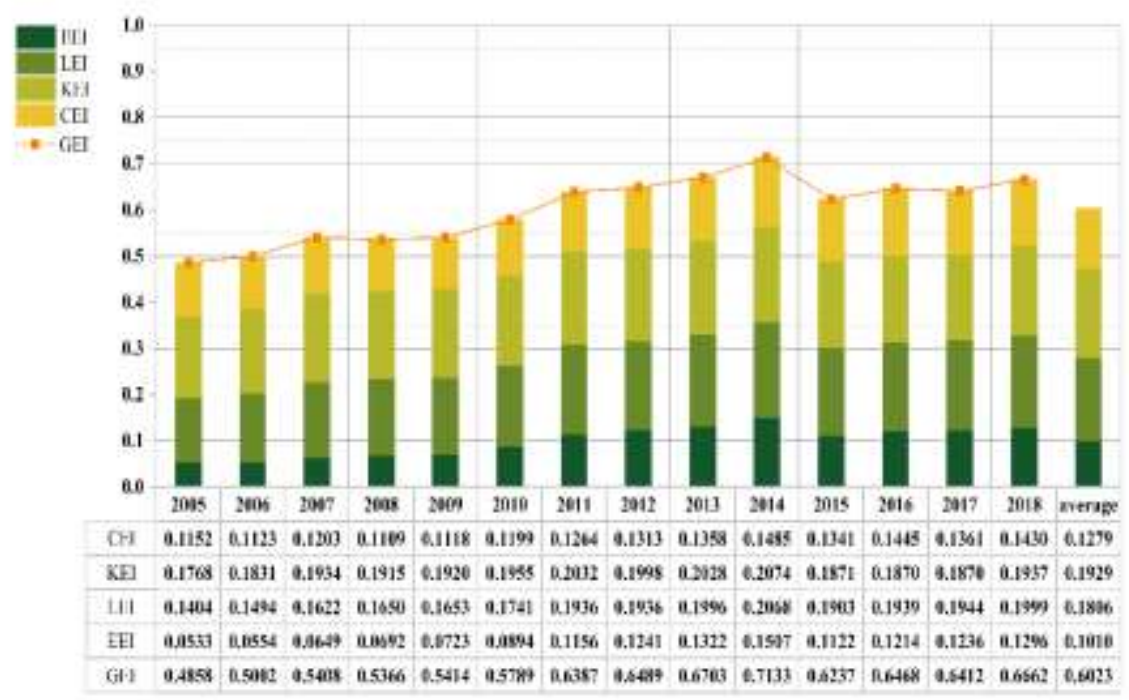

Fig. 1 GEI and its decompositions during 2005-2018

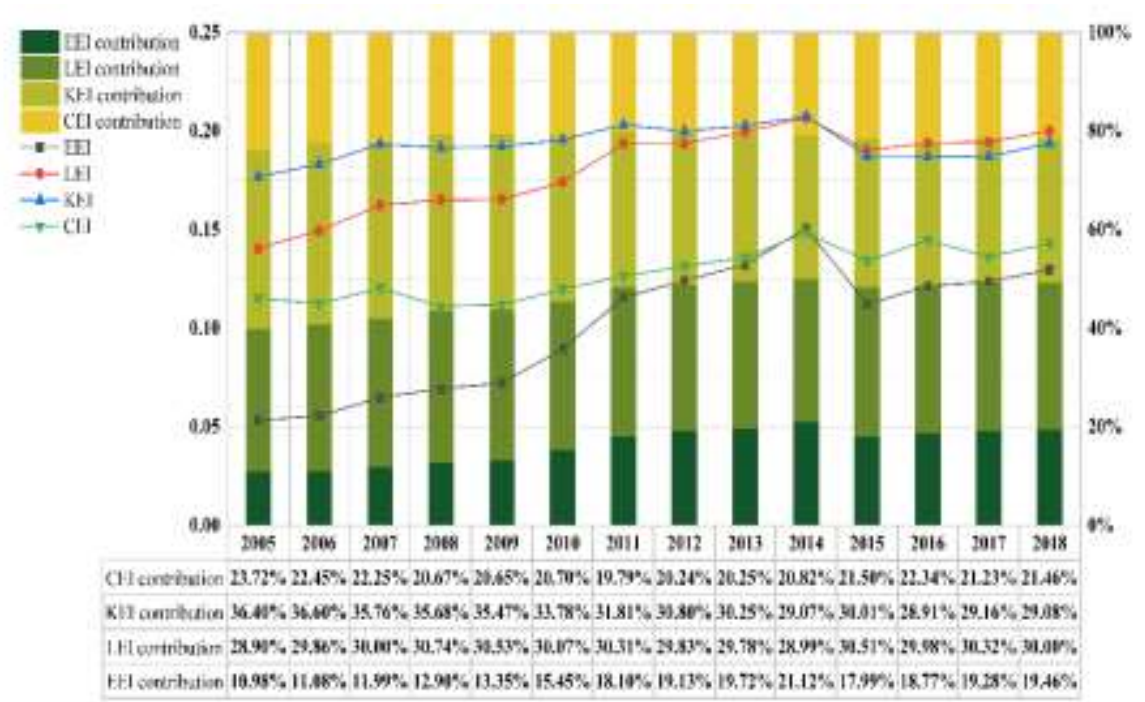




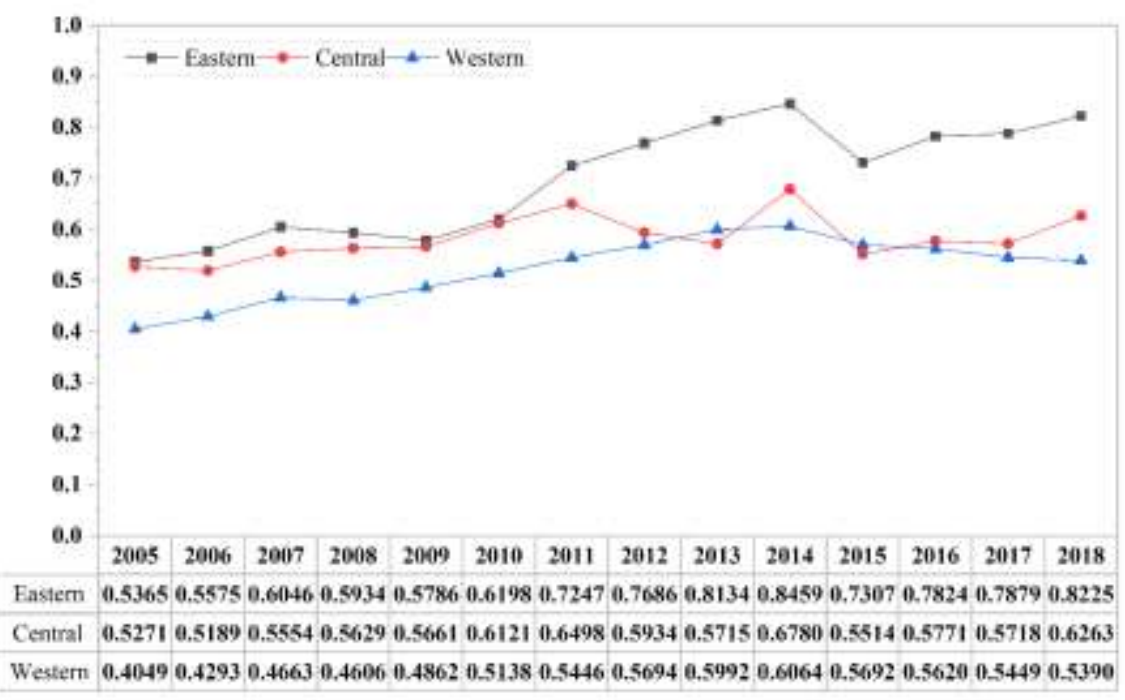

Fig. 3 GEI in three regions: 2005-2018
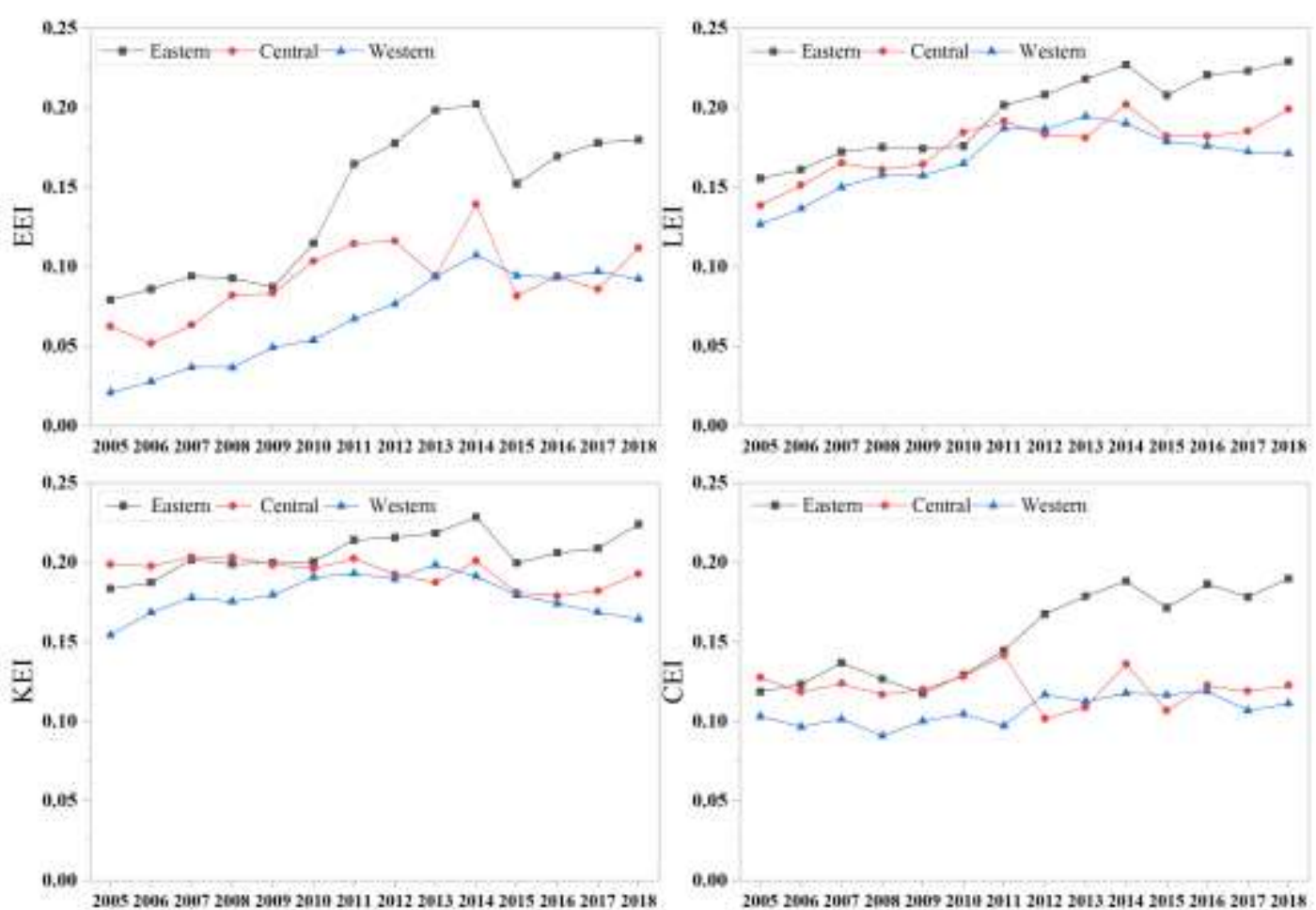

Fig. 4 Sources of GEI in three regions: 2005-2018 


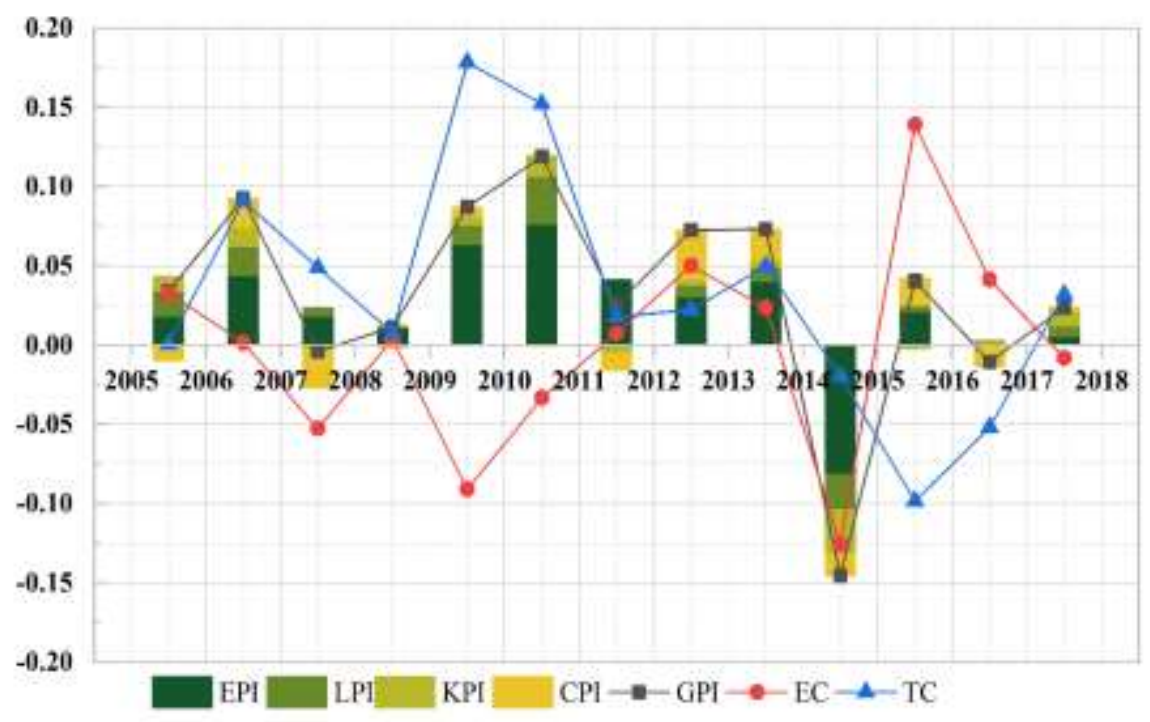

Fig. 5 Dynamic evolution of GPI and its decompositions: 2005-2018

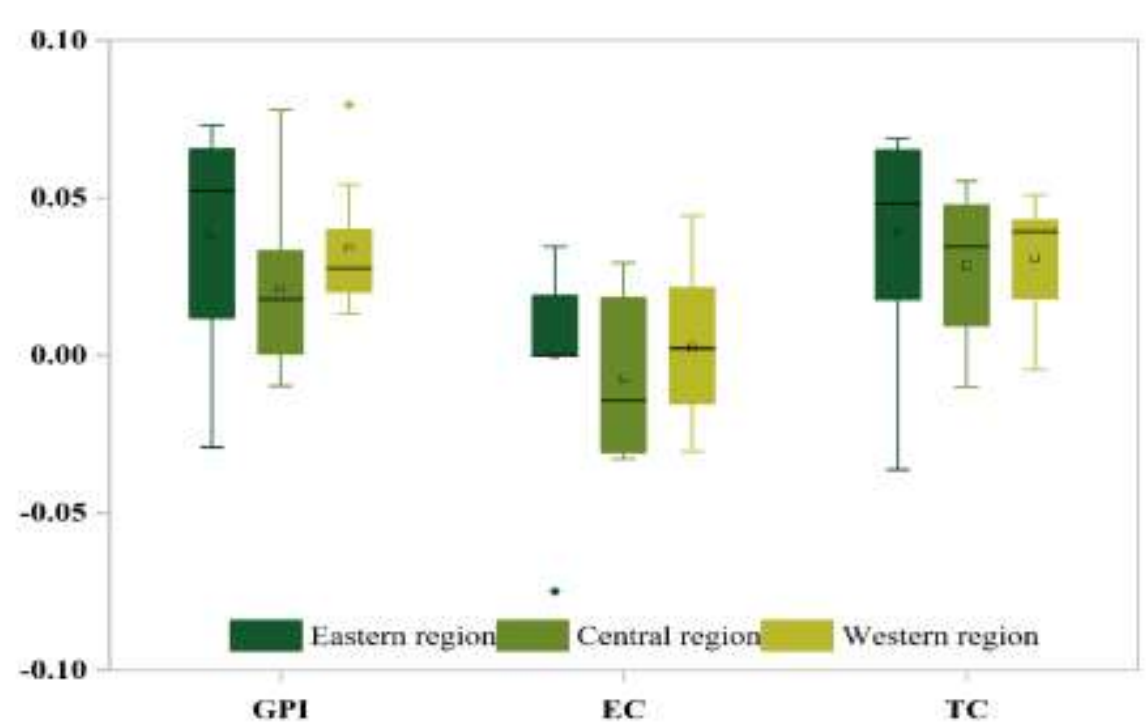

Fig. 6 GPI, EC and TC in three regions 


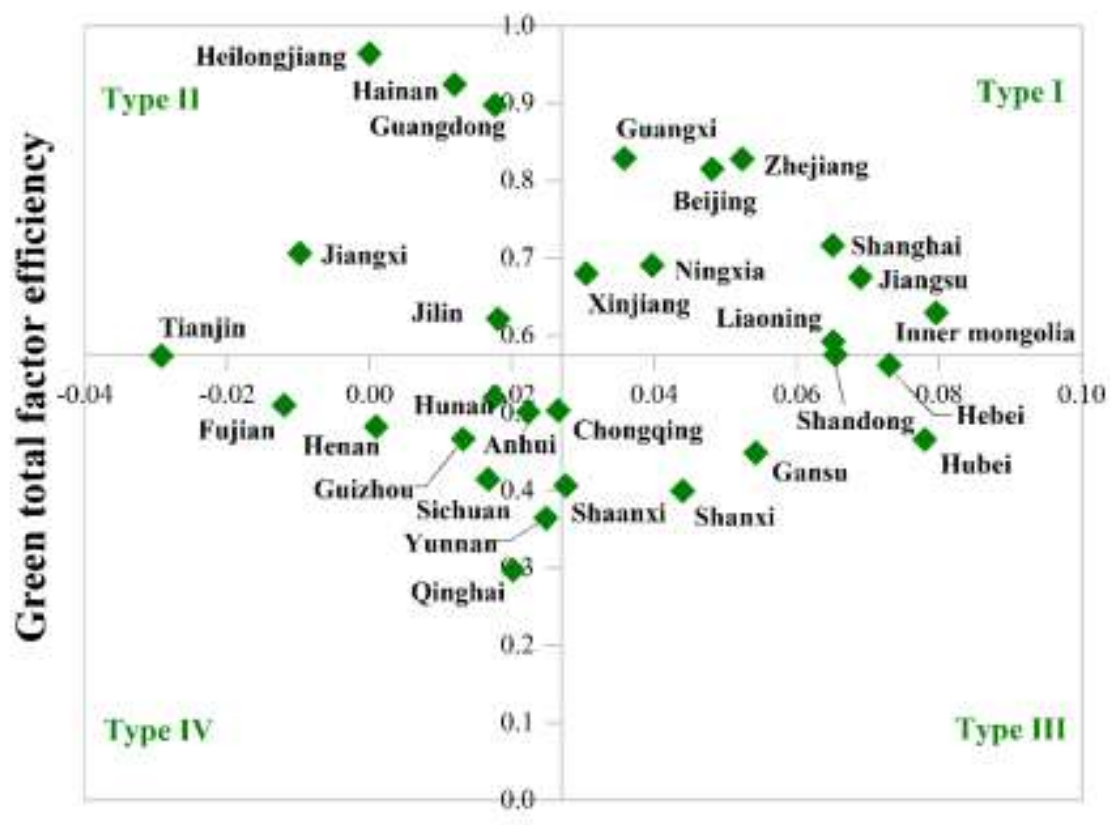

Green total factor productivity

Fig. 7 Green total factor performance of 30 provinces in China

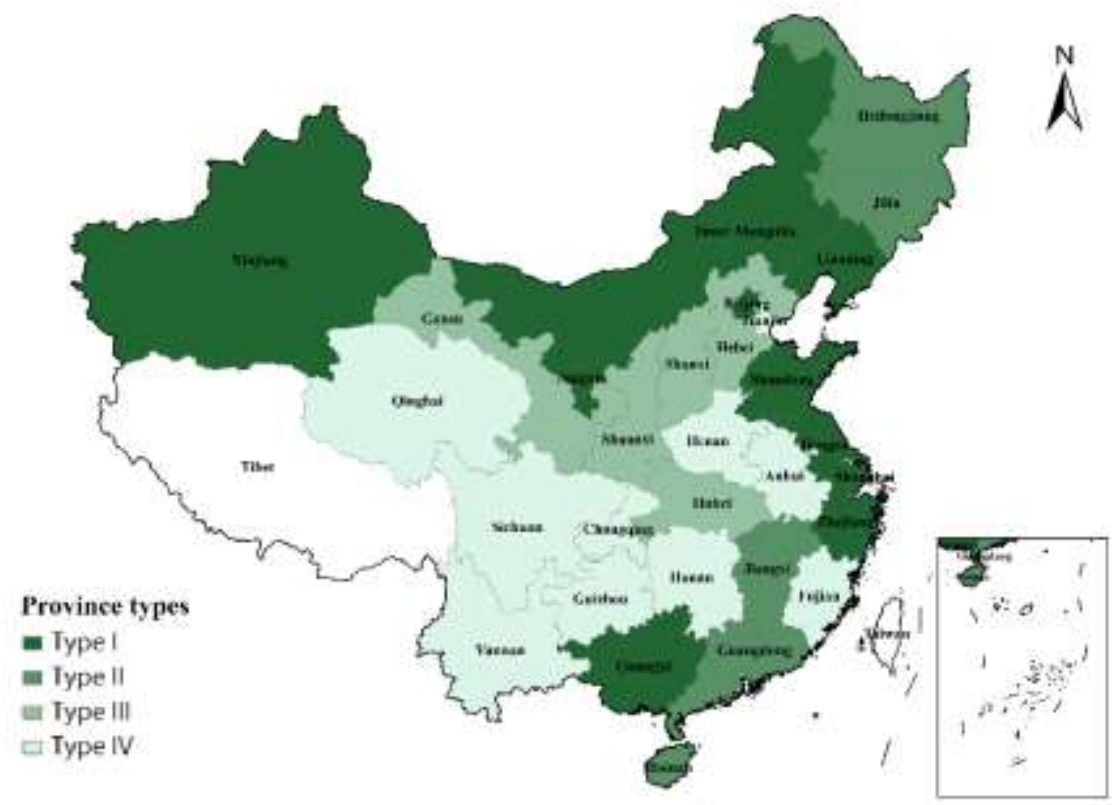

Fig. 8 Province division for green total factor performance of China's construction industry 